\title{
NOTAS
}

\section{El Matadero, pieza en tres actos}

Nos dice Esteban Echevarría en $E l$ matadero:* "la escena que se representaba en el matadero era para vista no para escrita". Y para vista - de ojos, de oído, de sensibilidad, de inteligencia - la presenta. Eleva con su cuento el ambiente grotesco del matadero a las dimensiones clásicas de la tragedia. Es, por lo tanto, la primera obra romántica en lengua española en que lo trágico y lo grotesco reunidos sirven al propósito de protesta social. Trágico desarrollo y romántico acento. Trágico, por la grandeza y energía del héroe - "que tenía un tío de sangre en las venas"1_ _ pronto a morir por lo que considera la dignidad del hombre. Trágico por la atmósfera de muerte necesaria que desde el comienzo se introduce, llegando al culmen en el epílogo. Trágico por la presencia del coro. Trágico, en fin, por la unidad de acción, de tiempo y de lugar.

Lo grotesco, al gusto romántico, se nota en el enfoque del cuadro: asciende el matadero a la condición de tema literario. ${ }^{2}$ Con él, todo lo que constituye su materia o su "fábula": carne, carniceros, ratas, perros, gaviotas, gente menuda. Al consejo de Víctor Hugo de ponerle un gorro frigio al diccionario - huir del lenguaje noble, de minorias - responde el escritor con el empleo del vocabulario vulgar. Volcado en la realidad, trata de sorprender a los personajes menores en su faena, otorgándoles plena

* Texto: Obras completas de Esteban Echeverría. Compilación y biografía por Juan María Gutiérrez. Ediciones Antonio Zamora. Buenos Aires, 1951, vol. I, pp. $427-442$.

1 Prueba de valor: ver el episodio de la muette de Caupolicán en La Araucana en que el alma del héroe se le escapa por cien heridas (Parte III, canto XXXIV).

2 Antes ya había tratado el autor de incorporar la pampa a la temática poética. Innova así por segunda vez. 
libertad de expresión. Se subraya la grandeza trágica del héroe - "víctima inerte" - expuesto a los "buitres" carnicetos, por la digna nobleza de sus palabras. Hiere con conceptos, ya que no se le permite herir con armas. El diálogo mantenido con los esbirros y el juez nos of rece la medida de su carácter. No se le admite, héroe que es, el tono soez de la "infame canalla":

- ¿Tiemblas? - le preguntó el juez.

-De rabia porque no puedo sofocarte entre mis brazos.

- ¿Tendrías fuerza y valor para eso?

-Tengo de sobre voluntad y coraje para tí, infame.

-A ver las tijeras de tusar mi caballo; túsenlo a la federala. [...]

- ¿Por qué no traes divisa?

-Porque no quiero.

- ¿No sabes que lo manda el Restaurador? libres.

- La librea es para vosotros, esclavos, no para los hombres

-A los libres se les hace llevar a la fuerza.

- Sí, la fuerza y la violencia bestial. Esas son vuestras armas, infames. El lobo, el tigre, la pantera también son fuertes como vosotros. Deberiais andar como ellas, en cuatro patas.

$-{ }_{-}$No temes que el tigre te despedace?

- Lo prefiero a que manietado me arranquen, como el cuervo, una a una las entrañas.

- ¿Por qué no llevas luto en el sombrero por la heroína?

-Porque lo llevo en el corazón por la patria, por la patria que vosotros habéis asesinado, ¡infames!

[...]

- iInsolente! Te has embravecido mucho. Te haré cortar la lengua si chistas. Abajo los calzones a ese mentecato cajetilla y a nalga pelada dénle verga, bien atado sobre la mesa.

[...]

-Primero degollarme que desnudarme, infame canalla.

Se establece, entonces, la desmesuradá distancia que media entre la dignidad del héroe y la baja condición de los verdugos. Uno, de trágica altivez. Los otros, de romántica invención, sacados de la realidad y transfigurados por espejos de grotescas imágenes para servir al objetivo del autor. No faltó al grupo la figura del machón sanguinario - Matasiete- 
ni la del juez venal. Todo se presta a la necesaria distinción que se debe hacer entre civilización y barbarie - dicotomía consagrada por Sarmiento en Facundo. El Romanticismo precursor nos ofrece aquí la visión de los dos mundos que coexisten pero no conviven. Por eso, recursos clásicos $y$ románticos intensifican a la vez el mensaje. Imposible valerse tan sólo de las tintas graves y de la noble serenidad de los trágicos griegos: inadmisible imaginar en tal situación otro héroe, otras voces o algún inútil cambio de lugar, tiempo o acción. No hay que someterse a aquél o a ese proceso de composición. Todo es válido, siempre que sirva a los intereses de la creación. En este caso, el sentido social y político de protesta. Romántico defensor del pueblo, devoto de la libertad y la justicia, Echeverría actúa como escritor engagé. La pluma al servicio de la causa que profesa.

Por haberse puesto al lado del dictador, valiéndose del poder para disfrutar de ciertos privilegios, la Iglesia y sus ministros son los primeros en sufrir las ironías del autor:

Estábamos, a más, en Cuaresma, época en que escasea la carne en Buenos Aires, porque la Iglesia, adoptando el precepto de Epicteto, sustine, abstine (sufre, abstente) ordena vigilia y abstinencia a los estómagos de los fieles [...] Y como la Iglesia tiene $a b$ initio y por delegación directa de Dios, el imperio inmaterial sobre las conciencias y estómagos, que en manera alguna pertenecen al individuo, nada más justo y racional que vede lo malo.

Los abastecedores, por otra parte, buenos federales, $y$ por io mismo buenos católicos, sabiendo que el pueblo de Buenos Aires atesora una docilidad singular para someterse a toda especie de mandamiento, sólo traen en días cuaresmales al matadero los novillos necesarios para el sustento de los niños y de los enfermos dispensados de la abstinencia por la Bula y no con el ánimo de que se harten algunos herejotes, que no faltan, dispuestos siempre a violar los mandamientos carnificinos de la Iglesia, y a contaminar la sociedad con el mal ejemplo.

Logra, finalmente, explicar el motivo del conubio que sirve a los intereses del Estado: "el caso es reducir al hombre a una máquina cuyo móvil principal no sea su voluntad sino la de la Iglesia y el gobierno". Tiene, pues, más de superstición que de fe la religión que practican. Y está especialmente ahí la importancia del primer acto de la pieza en que los predicadores funcionan como coro. 
Ubicados en el tiempo — "Por los años de Cristo de $183 \ldots$. . [... "en Cuaresma", y en el espacio _-"Buenos Aires"_, sólo unos falta el suceso $^{3}$ - "una lluvia muy copiosa" - por sobre "el amago de un nuevo diluvio" y el "murmullo de beatos y beatas [ . . ] haciendo novenarios y continuas plegarias". Se eleva entonces la voz en unísono de los predicadores. Imposible dejar de atribuirle valor y función coral. Exclamaciones, apóstrofes, crescendi de trágicas resonancias llegan a nuestros oídos:

¡Ay de vosotros, pecadores! ¡Ay de vosotros unitarios impíos que os mofáis de la Iglesia, de los santos, y no escucháis con veneración la palabra de los ungidos del Señor! ; Ah de vosotros, si no imploráis misericordia al pie de los altares! Llegará la hora tremenda del vano crujir de dientes y de frenéticas imprecaciones. Vuestra impiedad, vuestras herejías, vuestras blasfemias, vuestros crímenes horrendos, han traído sobre nuestra tierra las plagas del Señor. La justicia del Dios de la Federación os declarará malditos.

Silenciado el coro, se dirige nuestra atención a la escena. Sigue la lluviá como para acreditar "el pronóstico de los predicadores". Al fin del primer acto, bajan las aguas del Plata. Cesa la inundación. Pero no su daño. Carestía de carne, abstinencia, Cuaresma, lluvia nos traen el segundo cuadro. Se mueve el coro. Ahora, una comparsa de muchachos. A nuestros ojos se presenta un "espectáculo animado y pintoresco, aunque reunía todo lo horriblemente feo, inmundo y deforme de una pequeña clase proletaria peculiar del Río de la Plata". El autor trata en seguida de situarnos, dándonos, como confiesa, "un croquis de la locaiidad".

Hay nuevamente voces que se confunden, gritos, aullidos de perros," hasta que se distinguen, claramente, los "dichos y gritería desacompasada de los muchachos".

-Ahí se mete el sebo en las tetas, la tía-gritaba uno. $[\cdots]$

-Aquél lo escondió en el alzapón - - replicaba la negra.

3 Interesarte señalar la proposición que lo introduce: "Sucedió, pues, en aquel tiempo, una lluvia muy copiosa". El autor no lo había mencionado antes. Emplea, sin embargo, la conjunción pues. ¿Estaría la justificación en el período inicial en que fue citada el arca de Noé? ¿O se le escapó un pues sin nexo con los párrafos anteriores? beatos.

4 En la primera escena esas voces indistintas venían de los rezos de los 
- iA la bruja! ¡A la bruja! -repitieron los muchachos-. ¡Se lleva la riñonada y el tongorí! [ ....]

Cruzan otros grupos el escenario. El más interesante, el de las africanas, había sido anteriormente presentado. Así lo vemos: "Multitud de negras rebusconas de anchuras, como los caranchos de presa, se desbandaron por la ciudad como otras tantas arpías prontas a devorar cuanto hallaran de comible". En medio de la acción, nuevamente aparecen descritas como "negras y mulatas achuradoras, cuya fealdad trasuntaba las arpías de las fábulas". y pasan a constituir la presencia más notable, sin embargo no se les pueden distinguir las palabras. Entre sangre, entrañas, tripas y vejigas el animado mundo del matadero se ofrece como espectáculo:

Hacia otra parte, entre tanto, dos africanas llevaban arrastrando las entrañas de un animal. Allá una mulata se alejaba con un ovillo de tripas y resbalando de repente sobre un charco de sangre, caía a plomo, cubriendo con su cuerpo la codiciada presa. Acullá se veían acurrucadas en hilera 400 negras destejiendo sobre las faldas el ovillo y arrancando uno a uno los sebitos que el avaro cuchillo del carnicero había dejado en la tripa como rezagados, al paso que otras vaciaban panzas y vejigas para depositar en ellas, luego de secas, la achura:

El interés dominante del acto será el animal "sobre cuyos órganos genitales no estaban conformes los pareceres porque tenía apariencias de toro y de novillo". "Llególe su hora". Vuelve el coro. Con vocabulario propio, adecuado a la circunstancia:

-Al diablo los torunos del Azul.

- Mal haya el tropero que nos da gato por liebre.

- Si es novillo.

- ¿No está viendo que es toro, viejo?

$[\ldots]$

-Es emperrado y arisco como un unitario.

[…]

-iMueran los salvajes unitarios!

[…]

-El matambre a Matasiete, degollador de unitarios. iViva Matasiete!

-iA Matasiete el matambre! 
-Allá va - grito una voz [...]; Allá va el toro!

- AAlerta! ¡Guarda los de la puerta! ¡Allá va furioso como un demonio!

Matasiete, el facineroso matarife, pontifica en esos instantes de sangre y fuerza bruta. El niño degollado poca atención merece de los carniceros, del autor, del público. Acompañan nuestras miradas los jinetes "que no vieron la catástrofe". Aunque se refiera, en passant, a la tan trágica muerte, lo hace Echeverría de modo magistral. Creemos ver en ese trozo una de las expresiones más cabales de lo que llama Guillermo Díaz-Plaja "el reverso de la belleza":

Dióle el tirón el enlazador sentando su caballo, desprendió el lazo de la asta, crujió por el aire un áspero zumbido y al mismo tiempo se vio rodar desde lo alto de una horqueta del corral, como si un golpe de hacha la hubiese dividido a cercén, una cabeza de niño cuyo tronco permaneció inmóvil sobre su caballo de palo, lanzando por cada arteria un largo chorro de sangre.

Se termina el cuadro con la visión de Matasiete, "brazo y cuchillo ensangrentado", orgulloso de su hazaña, inclinado sobre el animal inerte. Se exhiben los enormes testículos, "signo inequívoco de su dignidad de toro". Risa y charla a media voz dan inicio al tercer acto. Coro: los carniceros. Al grito " ¿Allí viene un unitario!", reconocemos al protagonista de la última escena.

Llegamos al momento culminante de la pieza. Antes, los entusiasmos de la turba aguijonearon a los perseguidores del animal sobre cuyo valor tenían dudas. Al hombre también se le considera animal. Menos que toro. Menos que novillo: "perro". "Perto unitario". El mismo matarife, cuya presencia poblara el segundo acto en sus últimos instantes, daga en puño, todavía sucia de la sangre del toro, se presenta como anti-héroe. 5

Tan rápido es el cambio del centro de interés - del toro al hombreque el público tal vez no llegue a percibir la intención del autor. Es decir, en esos días solían atribuir mayor importancia a un toro y a sus testículos que a un hombre revestido de dignidad. $Y$ si lo encuentran

5 Podríamos ver en el enfoque de los dos personajes la clásica ecuación del "la raison du plus fort est toujours la meilleure". Y la fábula, como sabemos, se presta, a maravilla, a la dramatización. También, si nos proyectásemos en el tiempo, llegaríamos al moderno western que explota idéntica situación. Se prueba, entonces, a saciedad, ser el hombre, desde los tiempos de Caín y Abel, el mismo animal. ¿Terrible y monótona mismidad! 
tratan de rebajarlo a la más abyecta condición para dar escape al resentimiento insaciable. La postura de Matasiete es la misma frente a la bestia, frente al hombre.

Compárense:

Matasiete se tiró al punto del caballo, cortóle el garrón de una cuchillada y gambeteando en torno de él con su enorme daga en la mano, se la hundió al cabo hasta el puño en la garganta, mostrándola en seguida humeante y roja a los espectadores. [...] vaciló y cayó el soberbio animal entre los gritos de la chusma que proclamaba a Matasiete vencedor y le adjudicaba en premio el matambre.

Igual furia y ánimo demuestra al enfrentarse con el "salvaje unitario":

Matasiete, dando un salto, le salió al encuentro y con fornido brazo, asiéndolo de la corbata, lo tendió en el suelo tirando al mismo tiempo la daga de la cintura y llevándola a su garganta.

Una tremenda carcajada y un nuevo viva estentóreo volvió a vitorearlo.

Al oírse el coro, claramente se manifiesta el propósito de nivelar hombre y bestia. Salta a la boca de uno de los carniceros en forma de comparación: "Está furioso como un toro montaraz".

La presentación es casi la misma: el muchacho perseguido, maniatado, torturado, reacciona como el animal que

acosado por los gritos y sobre todo por las picanas agudas que le espoleaban la cola, sintiendo flojo el lazo, arremetió bufando a la puerta, lanzando a entrambos lados una rojiza y fosfórica mirada.

Del joven se dice:

Sus ojos de fuego parecían salirse de las órbitas, su negro $y$ lacio cabello se levantaba erizado. Su cuello desnudo y la pechera de su camisa dejaban entrever el latido violento de sus arterias y la respiración anhelante de sus pulmones.

Se habla de su "rojiza y fosfótica mirada" y de sus "ojos de fuego". 
Después de asistir a la loca carrera del toro, el público puede verlo pialado pero no rendido a la fuerza de los perseguidores:

Brincaba haciendo hincapié y lanzando roncos bramidos. [...] su brío y su furia redoblaron; su lengua, estirándose convulsiva, arrojaba espuma, su nariz humo, sus ojos miradas encendidas.

¿Y el unitario? Cabe señalar la identidad de la descripción:

Encogíase el joven, pateaba, hacía rechinar los dientes. Tomaban ora sus miembros la flexibilidad del junco, ora la dureza del fierro y su espina dorsal era el eje de un movimiento parecido al de la serpiente. Gotas de sudor fluían por su rostro grandes como perlas; echaban fuego sus pupilas, su boca espuma, y las venas de su cuello y frente negreaban en relieve sobre su blanco cutis como si estuvieran repletas de sangre.

Pari passu se cumplen los sacrificios. No se asemeja, empero, el momento fatal. Echeverria lo ha coronado en el último cuadro, de trágica trascendencia. Muere el bravo toro en manos de Matasiete. No el valiente muchacho. La muerte, él mismo se la ha buscado, huyendo de la suprema humillación de que se le mezclase la sangre a la del toro. Incapaz ya de defenderse de los enemigos, toma contra ellos la venganza del orgullo: no admite morir por ajena voluntad. Su muerte proviene del deseo consciente de adelantarse al cuchillo homicida. Muere porque quiere. En una autoafirmación de hombría, sin otra arma que la voluntad. El unitario da, con su muerte, lección de energía y superioridad a los buitres carniceros.

"-iPrimero degollarme que desnudarme, infame canalla!" - -son sus últimas palabras.

Para él no hubo requiem ni pavana. No se le enseñaron los órganos sexuales como prueba de valor. Ni tampoco hubo motivo para risas de ambiguo gusto. El coro le rindió homenaje de inmovilidad y estupefacción.

"Los sayones quedaron inmóviles y los espectadores estupefactos". Las expresiones finales nos dan la medida de su grandeza heroica:

-Reventó de rabia el salvaje unitario - dijo uno.

- Tenía un río de sangre en las venas —articuló otro.

El Matadero es reconocido como el primer cuento de la literatura 
argentina. Creemos poder ir más lejos: con él empieza el drama moderno en que se funden armónicamente la dignidad de la tragedia clásica y el vulgar y animado espectáculo del pequeño proletariado. Una nueva lectura será suficiente para comprobarlo.

María de José Queiroz

Indiana University 
